\title{
Effect of Polycythemia on Serum Lipid Profile and Oxidative Stress
}

\author{
Zainab Qasim ${ }^{1}$, Muhammad Al-Yasiri ${ }^{1}$ \\ ${ }^{1}$ Assistant Lect., Biology Department, College of Education for Girls, DhiQar University, Iraq
}

\begin{abstract}
Polycythemia is generally known as a disorder that affects the stem cells in the bonemarrow and is characterized by a high and excessive production of red blood cells. The current study was designed to investigate and investigate the relationship between the serum lipid profile and oxidative stress in polycythemia patients., The study included examining 85 blood samples from both gender, males and females, for patients coming to Shatra General Hospital. During the study period, all of (Hb, PCV, MDA, TC, TG, HDL, LDL, and VLDL) were examined for both patients and control groups.
\end{abstract}

The current study showed an increase in the incidence of polycythemia in males, while it decreased in females, and the study showed that the incidence of polycythemia increased with age until it reached its peak in the third age group 41-50 years, then the percentage gradually decreased to a minimum in the fifth age group 61-70 years .

The results of the study recorded a significant increase $\mathrm{P}<0.05$ in both the concentration of hemoglobin $\mathrm{Hb}$ and the packed cell volume PCV in patients with polycythemia, both real and secondary, when compared with the control group. Also, the results of the present study showed: a significant decrease $\mathrm{P}<0.05$ in cholesterol concentration in the group of true polycythemia compared with the control group. A significant increase $\mathrm{P}<0.05$ in concentration of triglycerides (TG) was higher in the true polycythemia group and a high significant $\mathrm{P}<0.05$ in the secondary polycythemia group compared with the control group.

The results indicated that there was a significant decrease $\mathrm{P}<0.05$ in LDL concentration in the true polycythemia group, and a significant increase of $\mathrm{P}<0.05$ in the secondary polycythemia group compared with the control group. The results of the study also recorded a high significant decrease $\mathrm{P}<0.05$ in the true polycythemia group and a significant decrease $\mathrm{P}<0.05$ in the secondary polycythemia group compared to the control group. The results also showed a significant increase $\mathrm{P}<0.05$ with the concentration of VLDL in the group of true polycythemia and high Significant $\mathrm{p}<0.05$ in the secondary polycythemia group compared with the control group.

The results showed a significant increase $\mathrm{P}<0.05$ in MDA concentration in polycythemia patients compared with the control group.

Keywords: Polycythemia, lipid profile, oxidative stress.

\section{Introduction}

Polycythemia: Polycythemia is generally defined as a disorder of the stem cells in the bone marrow

\section{Corresponding Author:}

\section{Zainab Qasim}

Assistant Lect., Biology Department, College of

Education for Girls, DhiQar University, Iraq

e-mail: ssarizvi06@gmail.com characterized by the abnormally high and excessive production of red blood cells ${ }^{(1)}$.

Polycythemia is a Greek term synonymous with Erythrocytosis, and literally translates to many cells in the blood ${ }^{(2)}$. Polycythemia is an uncommon clinical discovery, and one of its most important features is an increase in the number of red blood cells, as well as an increase in the concentration of hemoglobin $(\mathrm{Hb})$.and packed cell volume $(\mathrm{PCV})^{(3,4)}$. 
Blood cells are formed by the process of erythropoiesis, and this process is controlled by the feedback mechanism, as erythropoiesis is inhibited when,the number of blood cells exceeds the normal limit, and the process stimulates when a decrease in the number of, red blood cells occurs as in anemia or in the case of lack of oxygen and this control depends on, the hormone Circulating in the blood called erythropoietin, which is secreted primarily by the kidneys, where the bone marrow receptors respond to it, stimulating the production of red blood cells in it, which soon leaves, it into the bloodstream to start its cycle and function in .the gas transport, and thus the red blood cell count in the blood remains,almost constant and the capacity of Transporting oxygen in the blood. is always sufficient for the body's needs, although,red blood cells are affected by many factors. such as age, gender, nutritional status, health status, and height above sea level ${ }^{(5)}$

\section{Polycythemia is classified into two types:}

1. Relative Polycythemia: The relative polycythemia has been called: (Pseudo-polycythemia) is a condition in which. an increase in the size of PCV cells occurs while the total mass of red blood cells (RCM) remains within normal limits. and this occurs as a result of fluid deficiency and dehydration that lead to :a decrease in blood plasma compared to; cells as in the case of dehydration, diarrhea, vomiting and use Diuretics, capillary leak syndrome,; and severe burns $^{(6)}$.

2. Absolute polycythemia: It means: the occurrence of a primary or secondary increase in. the proportion of the volume of packed cell volume PCV, and there is a real increase in the mass of red $\mathrm{RCM}^{(7)}$., and it is of two types:

A. Primary polycythemia (Polycythemia Vera): True polycythemia (PV) is due to intrinsic factors of red cell precursors and bone marrow with increased numbers of red blood cells, as well as leukocytes and platelets. The disease begins with a latent thrombotic stage .and is associated with an increased incidence of venous thromboembolism ${ }^{(1)}$.

It was found that there is a mutation that causes; true polycythemia vera disease, which occurs in a gene called (The Janus kinasez "JAK" 2), in exon 14 of chromosome 9 , and this mutation was; discovered in approximately $95 \%$ of patients with .polycythemia vera and about $50 \%$ of people with Essential thrombocytosis and primary; myelofibrosis ${ }^{(2)}$.
There was no accurate understanding of these thrombotic tendencies and the level of hematocrit (PCV) was, the only laboratory factor that showed a clear association with thrombosis and; clinical symptoms to a large extent of increased erythropoiesis ${ }^{(3)}$.

B. Secondary polycythemia: Erythropoietin; plays an essential role in controlling the production of red blood cells and is under the influence of partial pressure of oxygen gas (PO2). This hormone;has a primary role in the excessive production of red blood cells (Polycythemia) by increasing the sensitivity of; the bone marrow to this hormone or An increase in its production by the cells; in the kidneys due to the increase in the, effectiveness of these cells, regardless of the partial pressure of oxygen, Secondary erythrocytosis occurs as a result of; some diseases such as congenital heart disease, chronic respiratory disease, smoking, and living at altitudes where. oxygen is lacking ${ }^{(1)}$. On the other hand, secondary polycythemia has a lower risk of blood clotting; despite higher hematocrit levels ${ }^{(4)}$.

Polycythemia; can also increase blood viscosity, however there are no standard indicators of; the disease to predict vascular events. The oxidative stress that has been detected in many patients occurs due to an imbalance, between the generation of active oxygen species. and other free radicals and antioxidants, the blood becomes more viscous; and less able to flow through the blood vessels and organs of the body, and this slow, blood flow is responsible for much of Symptoms of this disease ${ }^{(2)}$.

Aim of Study: In light of the above,, we decided to conduct the current study in order to investigate the effect of polycythemia on the serum. lipid profile and oxidative stress by studying. the following criteria:

1. Measuring. the serum lipid profile represented by CHO, TG, HDL, LDL and VLDL.

2. Measuring of. serum MDA as biomarker for the oxidative stress.

3. Measuring, the packed cell volume (PCV) ratio.

4. Measurement of hemoglobin $\mathrm{Hb}$ level in the blood..

5. Identify the largest infection rate .among different age groups.

6. Comparing the infection rate between the two, gender and investigating the causes. 


\section{Materials and Method}

1. Blood Samples: Blood samples were, collected from Polycythemia patients during their visit, to Shatra General Hospital/Laboratory Unit. (85) samples, were obtained from these patients distributed between. two sexes during the research period, their ages ranged between $(20$ - 70) years., and they were examined in the hematology and biochemistry laboratories.;;

For the period from November./2017 to June/.2018, when $5 \mathrm{ml}$ of blood was taken for each sample., $2 \mathrm{ml}$ of the blood sample drawn in a test tube containing an anticoagulant. were placed for them to be tested for hemoglobin $(\mathrm{Hb})$. and the percentage. of packed cell volume (PCV) in the hematology laboratory, 3 $\mathrm{ml}$ were placed, in an anticoagulant-free test tube. Serum was obtained by placing these tubes in a centrifuge; at a speed of $3000 \mathrm{rpm}$ for 15 minutes. The serum was separated from the. thrombus by a micro pipette. Serum was placed in the labeled Eppendorf tubes,. For the purpose of performing serum lipid profile (VLDL, LDL, HDL, TG, TC) and oxidative stress index .(MDA) tests, the same amount of blood was drawn from;healthy people (40) samples and the same tests were performed. for them for comparison purposes as they are control samples.

2. Hemoglobin and PCV Measurement: Hemoglobin and packed cell volume, (PCV) were measured using a blood tester Coulter Horiba The Emerald Company of French origin.

\section{Measurement of serum Lipid profile.}

3-1. Measurement of Total Cholesterol (TC): The total cholesterol concentration was measured in the blood serum samples by using a colorimetric reflectance spectrophotometric method,.. according to the method of ${ }^{(8)}$. By following the in.,structions attached to the measuring. kit prepared by Randox - UK, which contains several solutions,. The concentration of, total cholesterol in the blood serum is measured after it has been oxidized and hydrolysed, by enzymes, as the index., quinonemine, consists of,hydrogen peroxide $\mathrm{H} 2 \mathrm{O} 2$ and 4-aminoantipyrine in the presence, of phenol and peroxidase.. The amount of Quinonemine formed with a red pigment,gives the cholesterol concentration.
3-2. Measurement of Triglycerides (T.G): The concentration of T.G was measured in the serum samples,by colorimetric reflectance spectrophotometry; according to the method ${ }^{(9)}$., by following the instructions attached. to the test kit for measuring the concentration of, T.G, imported from Randox UK, this kit contains several solutions, The principle. of measuring the concentration of T.G in serum is based on the hydrolysis of. enzymes to glycerol.

\section{3-3. Measurement of High-density lipoprotein} (HDL): HDL concentration. was measured directlyin serum samples. by colorimetric reflectance spectrophotometry. by following the instructions attached to the. test kit for measuring, the concentration of. HDL, imported from Randox UK, this kit contains. many solutions and reagents.

\section{3-4. Estimation of low-density lipoprotein (LDL)} and very low-density lipoprotein (VLDL): Its concentrations were calculated based on the Friedewald equation and according. to ${ }^{(10)}$ as follows:

$$
\begin{aligned}
& \text { LDL. }=\mathrm{TC}-(\mathrm{HDL}+\mathrm{VLDL}) \\
& \mathrm{VLDL},=\mathrm{TG} / 5
\end{aligned}
$$

\section{Estimation oxidative stress:}

4-1. Malondialdehyde (MDA) assay: The MDA concentration . $(\mathrm{nmol} / \mathrm{ml})$ in serum samples, for patients and control was measured as biomarker for the oxidative stress, which is, Lipid Peroxidation Product. in human serum, it was determined by using the, method which described by ${ }^{(11)}$

5. Determining the incidence of Polycythemia among males and females:

(Percentage of Polycythemia incidence) $\%=$

(Class number/The total number)*100

6. Divide Polycythemia patients into five age groups:

- The first age group. (20-30) years.

- The second age group, (31-40) years.

- The third age group, (41-50) years.

- $\quad$ The fourth age group, (51-60) years.

- $\quad$ The Fifth age group, (61-70) years. 
7. Statistical analysis: Statistical data,analysis was performed on SPSS 17.0 to determine the mean, standard deviation., and other variables . $p$ value less than 0.05 was considered statistically significant.

\section{Results}

Polycythemia relationship with gender: The current study showed an increase in the percentage of polycythemia infection. in males, which was $67.46 \%$, while it decreased in females to $32.54 \%$.

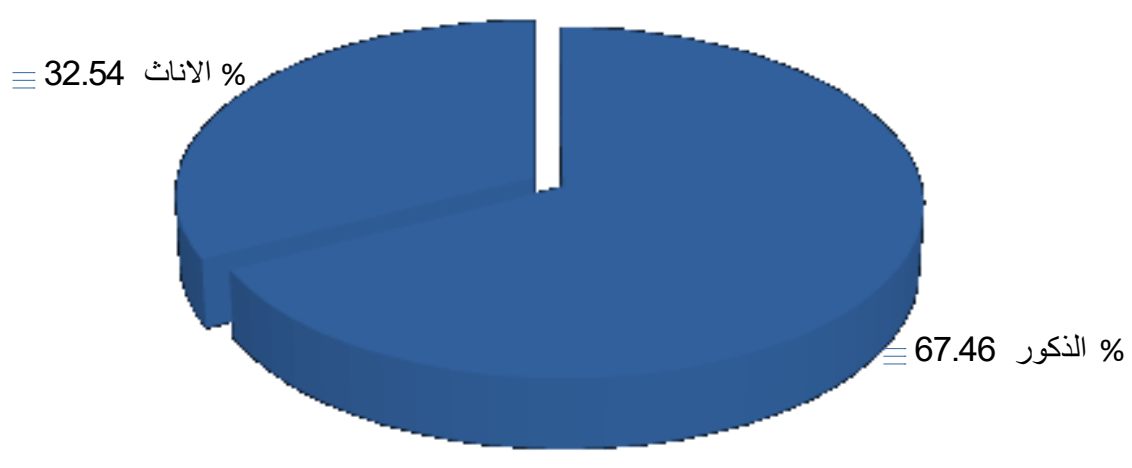

Figure 1: Polycythemiaincidence, depending on gender.

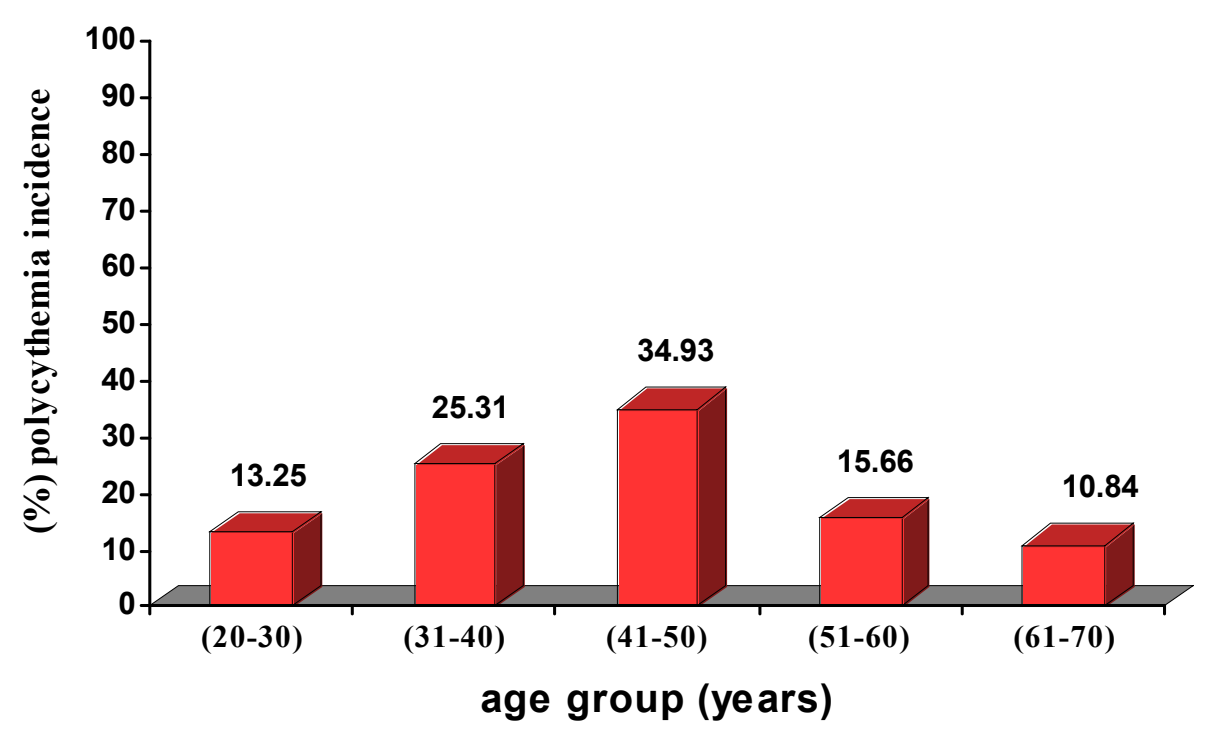

Figure 2: Distribution of age groups in polycythemia patients.

Polycythemia relationship with age: The current study showed, that the incidence of polycythemia .increased with age until it reached its peak in the third age group (41-50) years., and the rate was (34.93), then, the percentage gradually decreased to the lowest level, in the fifth age group (61-70) years,, and it was (10.84).

Effect of, polycythemia on concentration of hemoglobin and the PCV: The results of the current, study recorded a significant increase $(\mathrm{P}<0.05)$ in the hemoglobin concentration $(\mathrm{Hb})$ in patients with true and secondary polycythemia,: PV group (2) and non-
PV group (3), so the hemoglobin concentrations were. $17.48 \pm 1.30,17.15 \pm 1.24$ Respectively, compared to; the control group (1), where the $\mathrm{Hb}$ concentration was, $14.39 \pm 1.06$.

The results. also showed a significant increase (P $<0.05$ ) in (The packed cell volume $(\mathrm{PCV})$ in patients. with true and secondary polycythemia, group (2) and group (3), so the PCV percentage, was $56.70 \pm 2.42$, $55.68 \pm 2.32$, respectively, compared with the control. Group (1), which amounted to $41.84 \pm 1.61$, as shown in Table (1) below. 
Table (1): Effect of polycythemia on concentration of hemoglobin. and the PCV:

\begin{tabular}{|l|c|c|c|}
\hline Studied Parameters Groups & Hb $(\mathbf{g} / \mathbf{d L})$ & PCV (\%) & Number of samples \\
\hline (1) Control group & $14.39 \pm 1.06^{\mathrm{b}}$ & $41.84 \pm 1.61^{\mathrm{c}}$ & 40 \\
\hline (2) PV group & $17.15 \pm 1.24^{\mathrm{a}}$ & $56.70 \pm 2.42^{\mathrm{a}}$ & 40 \\
\hline (3) Non- PV group & $17.48 \pm 1.30^{\mathrm{a}}$ & $55.68 \pm 2.32^{\mathrm{b}}$ & 45 \\
\hline LSD & 0.34 & 0.59 & - \\
\hline
\end{tabular}

- The values represent the mean \pm the standard deviation.

- The letters a, b, c indicate a significant difference $(\mathrm{P}<0.05)$ between the studied groups depending on the value of LSD.

Effect of polycythemia on serum Lipid profile: The, results of the current study showed through Table (2) that there was a significant decrease $(\mathrm{P}<0.05)$ in total cholesterol, TC concentration in group (2) it was 159.20 \pm 22.59 compared; with the control group 193.02 \pm 5.92 , while the values of group (3) were 197.27 $\pm 15.96 \mathrm{An}$ approach to a control (1).

The results; also recorded a significant increase $(\mathrm{P}$ $<0.05)$ with the concentration of triglycerides TG in group (2) $148.59 \pm 43.27$ and a high, significant increase $(\mathrm{P}<0.05)$ in group (3) $179.56 \pm 61.71$ compared, to the control group (1) $119.83 \pm 10.77$.

The results indicated; a significant decrease ( $\mathrm{P}$ $<0.05)$ with LDL concentration in group (2) $92.45 \pm$
21.67 and a significant increase. $(\mathrm{P}<0.05)$ in group (3) $124.77 \pm 44.52$ compared; with the control group (1) $113.69 \pm 27.76$.

The results of the study,also recorded a high significant decrease $(\mathrm{P}<0.05)$ of HDL concentration in group (2) $42.02 \pm 10.35$; and a significant decrease $(\mathrm{P}<0.05)$ in group (3) $51.41 \pm 6.60$ compared, to the control group (1) $56.49 \pm 2.18$.

The results also showed, that there was a significant increase $(\mathrm{P}<0.05)$ with VLDL concentration in group (2) $29.86 \pm 8.06$ and; a high significant increase $(\mathrm{P}<0.05)$ in group (3) $35.92 \pm 9.42$,compared with the control group (1) $24.03 \pm 4.53$.

Table (2): Effect of polycythemia on serum Lipid profile:

\begin{tabular}{|l|c|c|c|c|}
\hline $\begin{array}{l}\text { Groups Studied } \\
\text { Parameters }\end{array}$ & (1) Control group & $\begin{array}{c}\text { (2) True polycythemia } \\
\text { (PV group) }\end{array}$ & $\begin{array}{c}\text { (3) Secondary polycythemia } \\
\text { (Non- PV group) }\end{array}$ & LSD \\
\hline TC $(\mathrm{mg} / \mathrm{dL})$ & $193.02 \pm 5.92^{\mathrm{a}}$ & $159.20 \pm 22.59^{\mathrm{b}}$ & $197.27 \pm 15.96^{\mathrm{a}}$ & 5.11 \\
\hline TG $(\mathrm{mg} / \mathrm{dL})$ & $119.83 \pm 10.77^{\mathrm{c}}$ & $148.59 \pm 43.27^{\mathrm{b}}$ & $179.56 \pm 61.71^{\mathrm{a}}$ & 14.78 \\
\hline LDL $(\mathrm{mg} / \mathrm{dL})$ & $113.69 \pm 27.76^{\mathrm{b}}$ & $92.45 \pm 21.67^{\mathrm{c}}$ & $124.77 \pm 44.52^{\mathrm{a}}$ & 10.67 \\
\hline HDL $(\mathrm{mg} / \mathrm{dL})$ & $56.49 \pm 2.18^{\mathrm{a}}$ & $42.02 \pm 10.35^{\mathrm{c}}$ & $51.41 \pm 6.60^{\mathrm{b}}$ & 1.91 \\
\hline VLDL $(\mathrm{mg} / \mathrm{dL})$ & $24.03 \pm 4.53^{\mathrm{c}}$ & $29.86 \pm 8.06^{\mathrm{b}}$ & $35.92 \pm 9.42^{\mathrm{a}}$ & 2.64 \\
\hline
\end{tabular}

- The values represent the mean \pm the standard deviation.

- The letters a, b, c indicate a significant difference $(\mathrm{P}<0.05)$ between the studied groups depending on the value of LSD.

Effect of polycythemia on Oxidative stress: The results of the current, study showed through Table (3) that there was a significant increase $(\mathrm{P}<0.05)$ in the MDA concentration, $(\mathrm{nmol} / \mathrm{ml})$ for a group of polycythemia patients, it was; $(0.49 \pm 0.04)$ compared to the control group that amounted to $(0.07 \pm 0.01)$. 
Table (3): Effect of polycythemia on Oxidative stress

\begin{tabular}{|l|c|c|c|}
\hline Groups Studied Parameter & (1) Control group & (2) Patients group & p value $^{\mathbf{a}}$ \\
\hline MDA (nmol/ml) & $0.07 \pm 0.01^{\mathrm{b}}$ & $0.49 \pm 0.04^{\mathrm{a}}$ & $<0.05$ \\
\hline Number of samples & 40 & 85 & - \\
\hline
\end{tabular}

Values are,expressed as mean $\pm \mathrm{SD}$.

a,b For significant comparison, between control and Patients groups.

\section{Discussion}

Polycythemia relationship with gender: Figure (1) shows that the percentage, of polycythemia infection in males increased to $67.46 \%$, while; it decreased in females to $32.54 \%$. The reason for this may be attributed to smoking,as this phenomenon is more common among males than in females.

There is also a relationship, between smoking and an increase in blood viscosity, as smoking causes a significant, increase in the total hemoglobin concentration in smokers compared to nonsmokers. This may be attributed to the, fact that smoking .leads to a decrease in the volume of blood plasma, which causes an increase in the mass of,red blood cells as a result of poor blood supply with oxygen and the lack of,hemoglobin binding With oxygen ( $\mathrm{Hb}-\mathrm{O})$, thus causing blood poisoning and increasing; its viscosity, the condition worsens with the increase in the duration. and number of smoking. These results are identical to those of ${ }^{(12)}$.

Smoking in all its; forms is considered one of the biggest pests that afflict society and has been described, by the Centers for Health Control and Prevention in the United States as the only preventable. and most important threat to human; health in developed .countries and is the most important cause of premature death worldwide ${ }^{(13)}$.

As polycythemia is an increase in the number of red blood cells in the blood that usually affects adults over the age of fifty, but it may affect people; in the age group between,fifteen to ninety, and it is more in men compared to women. It is the abnormal,increase in the number of red blood cells; The percentage of PCV hematocrit reaches more than $52 \%$,in men and more than $47 \%$ in women. Which leads to an increase in blood viscosity and the consequent, risks of complications ${ }^{(7)}$.

Polycythemia relationship with age: The current study indicates through Figure,(2) that the incidence of polycythemia,increased with age, until it reached its. peak in the third age group (41-50) years old, as the rate was, (34.93), after which the percentage gradually decreased; to a minimum in the fifth age group (6170) years, it was (10.84). The reason for this may be due to taking some medications, as it was observed that the hemoglobin level increased,significantly when diuretics were taken,, which leads to dehydration,. Also, an increase in the level was observed in severe burns. And stress ${ }^{(14)}$, high blood pressure, and also during long-term tobacco. smoking, as well as the increase, in psychological pressures and difficulties of life and the increase in responsibilities, in this particular age group and the accompanying. psychological and physical stress $^{(15)}$.

This increase. is true or primary when it includes an increase in the number of white blood cells and platelets in addition' to an increase in red cells, then it is called;(polycythemia vera), This occurs as a result of infection with some diseases such as congenital heart; disease and chronic respiratory disease, as well as smoking, and living on altitudes where oxygen is lacking $^{(1)}$. The cause of polycythemia; may also be a defect in the production of the hormone Erythropoietin, which. regulates the production of red blood cells, as in the case of various,body tumors such as those affecting the kidneys, liver, lung, brain and uterus, And the people at risk. of developing erythropoiesis are smokers and those with heart or lung disease And people exposed, to psychological,and physical stress, and people with a family history; of infection ${ }^{(2)}$.

As for the. gradual decrease in the incidence rate after this group, it may be due to the increase in deaths as an inevitable result after suffering, the afflicted person with many;diseases that exhausted his health and; claimed his life ${ }^{(6)}$.

Effect of polycythemia on concentration of hemoglobin and the PCV: The results; of the current study recorded through Table No. (1) the presence of a significant, increase $(\mathrm{P}<0.05)$ in both the concentration 
of hemoglobin. $(\mathrm{Hb})$ and the PCV packed cell volume, in patients with both types of real and secondary compared to the control group because these two indicators. are the most important characteristics of polycythemia As well as increasing the number of red blood cells., this is in agreement with a study presented by ${ }^{(7)}$.

Polycythemia vera is, a myeloproliferative disorder, when the body intensively produces red blood cells without. affecting the hormone erythropoietin,. While secondary polycythemia, is characterized by an increase in hemoglobin due to the effect. of that hormone ${ }^{(2)}$.

\section{Effect of polycythemia on serum Lipid profile:} Table (2) shows that there, was a significant decrease ( $\mathrm{P}$ $<0.05$ ) in the total cholesterol TC concentration. in group (2) true polycythemia, compared with control group,(1) While a non-significant increase was found in group (3) secondary polycythemia;compared to control group .

This is in agreement, with the study Fujita, H. et $a l .{ }^{(16)}$ where polycythemia PV is classified as necrotic tumors of the bone, marrow that reduce the level of cholesterol, as a result of the. increased demand for cholesterol by the damaged cell membranes in the bone. marrow ${ }^{(17)}$.

Also, there is a relationship; between the free cholesterol and the red blood cell count $\mathrm{RBC}, \mathrm{Hb}$ and PCV, It is expected, that the cause of the lack of cholesterol associated with polycythemia vera is the;retention and isolation of cholesterol spread coinciding, with an increase in RBC numbers, This does not occur in secondary,polycythemia due to an increase in all blood components without exception. and not RBC alone as in the case of polycythemia vera ${ }^{(16)}$.

The results; also recorded a significant increase (P $<0.05)$ in the concentration of triglycerides TG in group (2) and a high significant increase $(\mathrm{P}<0.05)$ in group (3) compared, to the control group (1). The reason for this may be due to smoking as well, as many indicated, From studies; to the presence of an increase; in the concentration of serum fats in the blood of smokers ${ }^{(12)}$.

The reason for this increase may be attributed to the fact that smoking works on the presence of different; mechanisms that lead to a change in the level of fats, the .most important of which are: Nicotine stimulates the,sympathetic nerves in the adrenergic gland, which leads to an increase, in the secretion of hormones (Epinephrine and norepinephrine), which leads to an increase; in the lipase enzyme and the concentration; of free fatty acids (FFA) in the plasma, and this leads to an increase in the secretion of (TC) and triglycerides, in the bloodstream $^{(18)}$.

The results indicated; a significant decrease (P $<0.05$ ) in the concentration of low-density lipoprotein LDL, in group (2) and a significant increase $(\mathrm{P}<0.05)$ in its concentration. in group (3) compared with the control group (1). The cause of the high fat may be the, consumption of diets rich in fat and cholesterol as well as a diet low in fiber and grain content. ${ }^{(14)}$.

As for the reason for the decrease in group (2), it may be attributed to the decrease in the cholesterol level of people with true polycythemia due to the presence of a close; association between them ${ }^{(19)}$.

The results of the study; also recorded a high significant decrease $(\mathrm{P}<0.05)$ in the concentration of, HDL lipoprotein in group (2) and a significant decrease $(\mathrm{P}<0.05)$ in group (3) compared, with the control group (1) and the reason may be that lipid metabolism can be It is altered by acute and chronic. infections that participate in increasing,plasma concentrations of cytokines, Studies have shown that a number of cytokines, such as tumor necrosis factor (TNF- $\alpha$ ) and interleukin (IL-1 $\beta$ ) are believed; to have effects on lipid metabolism and blood change dynamically ${ }^{(20)}$.

Lipolysis increases in adipose tissue, as is the removal of triglycerides neutralized,cholesterol (TG) and low-density lipoproteins (LDL) due to the decrease in the activity of the lipoprotein lipase enzyme. Thus, any case,raises the level of,cytokines (TNF- $\alpha$ ) and interleukin (IL-1 $\beta$ ).) In the blood that has the potential;to cause lipid-raising ${ }^{(14)}$.

The main features; of this catabolic state are lipid peroxidation, elevation of free fatty acids, elevated. cholesterol, level of neutrophilic triglycerides (T.G), and level of low-density, lipoproteins (LDL) ${ }^{(14)}$.

The increased concentration; of LDL in the blood of these,patients leads to the possibility of its deposition in the arteries unites with calcium, and leads to narrowing and hardening of .the arteries, and consequently the occurrence of thrombosis, and arteriosclerosis ${ }^{(19)}$.

High-density .lipoproteins levels (HDL) in the current study showed a significant decrease compared with,the control group. The reason for this may be 
attributed to the oxidative stress occurring in the;patients as a result of lipid peroxidation, which is, evident by the high concentration of MDA, and this is consistent with the .findings of Hamza et. al. ${ }^{(21)}$, which promotes lipolysis in .adipose tissues, and the plasma concentration of; free fatty acids increases as it moves to the liver and muscles, and in the liver. some free fatty acids are oxidized; and most of them are returned The process of esterification into (TG) increases. the level of (TG) in the blood and the level of HDL decreases ${ }^{(20)}$.

The results; also showed a significant increase ( $\mathrm{P}<0.05)$ with the .concentration of very low density, lipoprotein (VLDL) in group (2) and a high significant increase $(\mathrm{P}<0.05)$ in group (3) compared with the; control group (1). The reason for this may be attributed to the increase. In triglycerides, because there is a close relationship. between them, according to the equation ${ }^{(21)}$ :

$$
\mathrm{VLDL}=\mathrm{TG} / 5 .
$$

It was found that; a high level of triglycerides neutralized .cholesterol (TG) leads to an increase in the .level of very low-density lipoprotein (VLDL) because they contain a large proportion of triglycerides neutralized to cholesterol and thus lower, levels of high-density lipoproteins associated with cholesterol, HDL-C ${ }^{(14)}$.

\section{Effect of polycythemia on Oxidative stress:} The results of the current study showed a significant increase in malondialdehyde, (MDA) concentration in polycythemia,patients compared with the control group, which expresses the presence of oxidative; stress status as the final,product of lipid peroxidation., This is in agreement with results presented by Pérez - Rodríguez L, et $a l .{ }^{(14)}$ that .demonstrated,that lipid peroxidation index levels,(plasma levels of MDA and hydroperoxidase) contrast with levels of circulating lipids (triglycerides and cholesterol).

We studied MDA as an oxidative .stress parameter in polycythemia patients and found that there is a close correlation. between the lipid profile and the increased oxidative stress, which believed that, lead to conventional cardiovascular risk factors, and that the increase in lipid;peroxidation is due to the oxidative stress that occurs when peroxides override the antioxidant mechanism and the dynamic balance between oxidants and,antioxidants is disturbed ${ }^{(15)}$.
Several studies have confirmed the presence of a change in the serum lipid profile during oxidative stress, as well as; a relationship between atherosclerosis and coronary heart disease in patients .with polycythemia ${ }^{(1)}$.

Oxidative stress is caused by an increase. reactive oxygen radicals inside cells, Which in turn,leads to lipid peroxidation, Thus causing cell damage and then death, determination of serum MDA level gives an indication of lipid peroxidation levels ${ }^{(14)}$.

A study presented by Vener et al. ${ }^{(6)}$ show that the patients with polycythemia they have an increase in oxidative,stress and that this increase was associated with a high level of,homocysteine.

It has been suggested that increased, oxidative stress may be correlated with vascular events in as well as the mutagenesis such as JAK2V617F .mutation in PV patients ${ }^{(1)}$.

Aliyazicioglu Y, et al. ${ }^{(22)}$ shown. that JAK2V617F mutation played a major role in the pathogenesis of .myeloproliferative diseases, particularly PV, while some studies suggest, that JAK2V617F mutation .may not be the initiator of the disease, It has been found that oxidative stress, parameters were similar in patients who were negative and positive,for the JAK2V617F mutation $^{(2)}$. They considered that it is late;genetic event can occur in patients with myeloproliferative disease, and The role played by free radicals which causing DNA damage and cellular oxidative, damage pathways ${ }^{(14)}$.

\section{Conclusions}

1. The incidence of polycythemia is more common in males compared to females.

2. The age group (41-50) years is, the most likely to have polycythemia.

3. Increased hemoglobin $\mathrm{Hb}$ concentration; and compressed cell volume in patients with polycythemia, both true, and secondary types, PCV.

4. Decrease in cholesterol,concentration in true polycythemia patients compared with the control group.

5. An increase in the concentration .of triglycerides TG in patients with polycythemia.

6. Decreased concentration of HDL for people with polycythemia. 
7. The high concentration of low-density lipoprotein (LDL) in patients with secondary polycythemia and lower in those with true polycythemia.

8. The high concentration of MDA in patients with polycythemia.

9. There is a strong correlation;between oxidative stress and the lipid profile.

\section{Recommendations:}

1. Refrain from smoking .because smoking, leads to an increase in the non-oxidized hemoglobin,to more than $10 \%$ of the total hemoglobin rate, and this is accompanied by an increase in the number of .red blood .cells to compensate for the inability of the cells to transport oxygen.

2. Conducting a PCV analysis, the volume of compressed cells, as well as knowing, the percentage of hemoglobin in the blood, and constantly testing the complete blood picture;for patients with polycythemia to avoid the deterioration of the disease and try to correct it.

3. The existence. of a special record for every .family that has people with this disease to know the extent of the possibility of,transmitting it genetically.

4. Donating blood from time to time for people; with polycythemia.

5. Using aspirin under. the supervision of a doctor to reduce blood clotting and increase, its liquidity, and thus reduce the incidence of stroke or coronary heart disease.

6. The patient is advised to drink sufficient quantities of water regularly to maintain. the normal amount of fluids in the body and maintain. the health of the kidneys.

7. We advise the patient. to follow healthy eating method rich in antioxidants and to return to the food pyramid. And leave or reduce the. eating of red meat.

Ethical Clearance: The Research Ethical Committee at scientific research by ethical approval of both environmental and health and higher education and scientific research ministries in Iraq

Conflict of Interest: The authors declare that they have no conflict of interest. Funding: Self-funding

\section{References}

1. Durmus A, Mentese A, Yilmaz M, Sumer A, Akalin I, Topal C, et al. The thrombotic events in polycythemia vera patients may be related to increased oxidative stress. Medical Principles and Practice. 2014;23(3):253-258.

2. Akalin I, Armangil D, DURMUŞ A. Neonatal polycythemia may be free of JAK2V617F mutation. Türkiye Klinikleri Tip Bilimleri Dergisi. 2013;33(1):132-137.

3. Kilpivaara O, Levine RL. JAK2 and MPL mutations in myeloproliferative neoplasms: discovery and science. Leukemia. 2008;22(10):1813-1817.

4. Policitemia GIS. Polycythemia vera: the natural history of 1213 patients followed for 20 years. Annals of Internal Medicine. 1995;123(9):656664.

5. Eroschenko VP, Di Fiore MS. DiFiore's atlas of histology with functional correlations. Lippincott Williams \& Wilkins; 2013.

6. Vener C, Novembrino C, Catena FB, Fracchiolla NS, Gianelli U, Savi F, et al. Oxidative stress is increased in primary and post- polycythemia vera myelofibrosis. Experimental hematology. 2010;38(11):1058-1065.

7. McMullin MF. Idiopathic erythrocytosis: a disappearing entity. ASH Education Program Book. 2009;2009(1):629-635.

8. Allain CC, Poon LS, Chan CS, Richmond W, Fu PC. Enzymatic determination of total serum cholesterol. Clinical chemistry. 1974;20(4):470 475.

9. Coxon B, Schaffer R. Characterization and quantitative analysis of D-glucose for use in clinical analysis. Analytical chemistry. 1971;43(12):15651570.

10. Friedewald WT, Levy RI, Fredrickson DS. Estimation of the concentration of low-density lipoprotein cholesterol in plasma, without use of the preparative ultracentrifuge. Clinical chemistry. 1972;18(6):499-502.

11. Yagi K. Lipid peroxides and related radicals in clinical medicine. In: Free radicals in diagnostic medicine. Springer; 1994. p. 1-15.

12. Waqar A. Effect of tobacco smoking on the lipid profile of teenage male population in Lahore City. International Journal of Medicine and Medical 
Sciences. 2010;2(6):171-177.

13. El-Nachef WN, Hammond SK. Exhaled carbon monoxide with waterpipe use in US students. JAMA. 2008;299(1):36-38.

14. Pérez-Rodríguez L, Romero-Haro AA, Sternalski A, Muriel J, Mougeot F, Gil D, et al. Measuring oxidative stress: the confounding effect of lipid concentration in measures of lipid peroxidation. Physiological and Biochemical Zoology. 2015;88(3):345-351.

15. Birben E, Sahiner UM, Sackesen C, Erzurum $\mathrm{S}$, Kalayci O. Oxidative stress and antioxidant defense. World Allergy Organization Journal. 2012;5(1):9-19.

16. Fujita $H$, Hamaki $T$, Handa $N$, Ohwada A, Tomiyama J, Nishimura S. Hypocholesterolemia in patients with polycythemia vera. Journal of Clinical and Experimental Hematopathology. 2012; 52(2):85-89.

17. Vardiman JW, Thiele J, Arber DA, Brunning RD, Borowitz MJ, Porwit A, et al. The 2008 revision of the World Health Organization (WHO) classification of myeloid neoplasms and acute leukemia: rationale and important changes. Blood. 2009;114(5):937-951.
18. Shai I, Rimm EB, Hankinson SE, Curhan G, Manson JE, Rifai N, et al. Multivariate assessment of lipid parameters as predictors of coronary heart disease among postmenopausal women: potential implications for clinical guidelines. Circulation. 2004;110(18):2824-2830.

19. Grundy SM. Role of low-density lipoproteins in atherogenesis and development of coronary heart disease. Clinical chemistry. 1995;41(1):139-146.

20. Kontush A, Guérin M, Chapman MJ. Spotlight on HDL-raising therapies: insights from the torcetrapib trials. Nature Clinical Practice Cardiovascular Medicine. 2008;5(6):329-336.

21. Hamza MA, Abdulla IT, Hamza EA. Effect of oxidative stress on lipid profile and blood parameters to a sample of students at university of Zakho during exames. Tikrit Journal of Pure Science. 2018;23(1):78-82.

22. Aliyazicioglu Y, Demir S, Turan I, Cakiroglu TN, Akalin I, Deger O, et al. Preventive and protective effects of Turkish propolis on $\mathrm{H} 2 \mathrm{O}$ 2-induced DNA damage in foreskin fibroblast cell lines. Acta Biologica Hungarica. 2011;62(4):388-396. 